\title{
APLIKASI GO-WORK (APLIKASI LAYANAN INFORMASI BAGI TUNAKARYA)
}

\author{
Yeni Agus Nurhuda ${ }^{1)}$, Sela Rosalina ${ }^{2)}$ \\ 1), 2) Sistem Informasi, Universitas Teknokrat Indonesia \\ Jl. H.ZA Pagaralam, No 9-11, Labuhanratu,Bandarlampung \\ Email : agus.nurhuda@teknokrat.ac.id ${ }^{1}$, selarosalina05@gmail.com ${ }^{2)}$
}

\begin{abstract}
Abstrak
Makalah ini menyajikan produk hasil penelitian pengembangan dan implementasi aplikasi layanan bagi tunakarya pada Dinas Tenaga Kerja dan Transmigrasi di Provinsi Lampung. Penelitian dilatarbelakangi oleh minimnya media untuk deseminasi informasi layanan kepada tunakarya.

Aplikasi layanan bagi tunakarya di kembangkan untuk dapat diakses secara online dan mudah menggunakan smartphone berbasis sistem operasi android. Pengguna aplikasi adalah para pencari kerja (tunakarya), relawan yang dapat perorangan maupun instansi terkait, dan admin selaku pengelola system informasi. Materi yang disajikan dalam aplikasi meliputi informasi lowongan kerja dan informasi kegiatan pelatihan. Aplikasi juga dilengkapi dengan fasilitas tanya jawab antara pengguna tunakarya dan para relawan yang terdaftar.lowongan kerja dan informasi kegiatan pelatihan.
\end{abstract}

Kata kunci: tunakarya, smartphone, android.

\section{Pendahuluan}

Pengangguran merupakan jumlah tenaga kerja dalam perekonomian yang secara aktif mencari pekerjaan tetapi belum memperoleh pekerjaan. Tingginya tingkat pengangguran di suatu wilayah, menjadi sumber utama penyebab kemiskinan dan meningkatnya kerawanan terjadinya kriminal dan keresahan sosial. Salah satu faktor yang mempengaruhi tingginya jumlah pengangguran adalah rendahnya tingkat pendidikan $(\mathrm{N}$ Sirait, 2013)

Berdasarkan data Badan Pusat Statistik Lampung tahun 2017, jumlah pengangguran di Provinsi Lampung mencapai 176.257 orang yang terdistribusi di perkotaan sebesar 78.941 orang dan pedesaan mencapai 97.316 orang. Diperkirakan angka ini akan terus meningkat jika tidak segera mendapatkan penanganan serius dari pemerintah dalam menghadirkan lowongan dan kesempatan kerja. Berdasarkan data dan informasi yang dihimpun dari Dinas Tenaga Kerja dan Transmigrasi Provinsi Lampung, berbagai upaya untuk menurunkan angka pengangguran di Provinsi Lampung telah dilakukan, namun demikian tingkat partisipasi masyarakat dalam mengikuti program kegiatan yang dilakukan masih relativ rendah. Salah satu penyebabnya adalah Informasi mengenai kegiatan yang dilaksanakan tidak dapat terinformasikan dengan baik kepada masyarakat.

Teknologi Informasi dan Komunikasi mengalami perkembangan yang sangat masif. Munculnya teknologi smartphone telah menandai munculnya era revolusi industri 4.0. Smartphone merupakan produk interaktif yang terdiri atas bagian antarmuka perangkat lunak dan antarmuka perangkat keras (Dinarah, Achmad, \& Irfansyah, 2017).

Kemudahan akses menjadi kata kunci dalam proses pendistribusian informasi kepada pihak berkepentingan. Berbagai informasi harus dikemas ulang agar informasi yang dibutuhkan dapat diakses secara mudah dan cepat (Pebriyanti, 2015). Penggunaan teknologi smartphone dengan aplikasi yang dirancang secara online dan dikembangkan guna menyuguhkan informasi yang telah dikemas ulang akan bisa dijadikan sebagai solusi dalam pendistribusian informasi secara luas dan mudah.

Dari segi pelayanan (services), akses internet dipergunakan untuk memberi pelayanan dalam rangka mendorong perubahan sosial bagi peningkatan kesejahteraan masyarakat (as an agent of social change) dan memberi pelayanan untuk mendukung perkembangan kinerja sector-sektor terkait (Usman, 2016).

\section{Masalah dan Tujuan}

Dalam makalah ini, penulis membahas hasil penelitian yang dilakukan penulis pada Dinas Tenaga Kerja dan Transmigrasi Provinsi Lampung yang mengangkat permasalahan mengenai bagaimana meningkatkan aksesibilitas informasi tentang program layanan bagi para tuna karya yang dilaksanakan oleh Dinas Tenaga Kerja dan Transmigrasi di Provinsi Lampung. Tujuan dari penelitian ini adalah untuk menghadirkan informasi kepada para tuna karya secara mudah melalui smartphone berbasis sistem operasi android.

\section{Metodologi}

Dalam penelitian ini dilakukan pengemasan ulang informasi tentang berbagai program bagi para tuna karya yang dilaksanakan oleh Dinas Tenaga Kerja dan Transmigrasi Provinsi Lampung yang kemudian dihadirkan dalam informasi yang dapat diakses melalui 
perangkat smartphone berbasis sistem operasi android. Data primer dihimpun dengan melaksanakan observasi langsung pada Kantor Dinas Tenaga Kerja dan Trnasmigrasi Provinsi Lampung dan wawancara kepada kepala bidang pelatihan dan produktifitas Disnakertrans dan beberapa Tunakarya yang berada di daerah Bandar Lampung dan sekitarnya.

Data primer yang terhimpun menjadi materi dasar dalam melaksanakan analisis kebutuhan pengguna untuk dipenuhi dan menjadi dasar dalam proses rancang bangun aplikasi. Rancang bangun aplikasi dibuat dengan menggunakan model Unified Modeling Language (UML) yang merupakan bahasa visual untuk pemodelan dan komunikasi mengenai sebuah sistem dengan menggunakan diagram dan teks-teks pendukung. Aplikasi pada smartphone berbasis sistem android dibangun dengan menggunakan android studio dan sistem administrasi aplikasi dibangun dengan menggunakan software Dream weaver.

\section{Pembahasan}

Aplikasi Go-Work (aplikasi layanan informasi bagi tunakarya) di rancang untuk digunakan oleh para tunakarya dengan latarbelakang sosial, pendidikan, budaya, dan domisili yang berbeda-beda. Aplikasi didesain agar mudah digunakan dengan cakupan informasi yang memadai bagi para pencari kerja.

Desain konseptual aplikasi dikembangkan dengan menggunakan model diagram use case seperti terlihat pada gambar 1

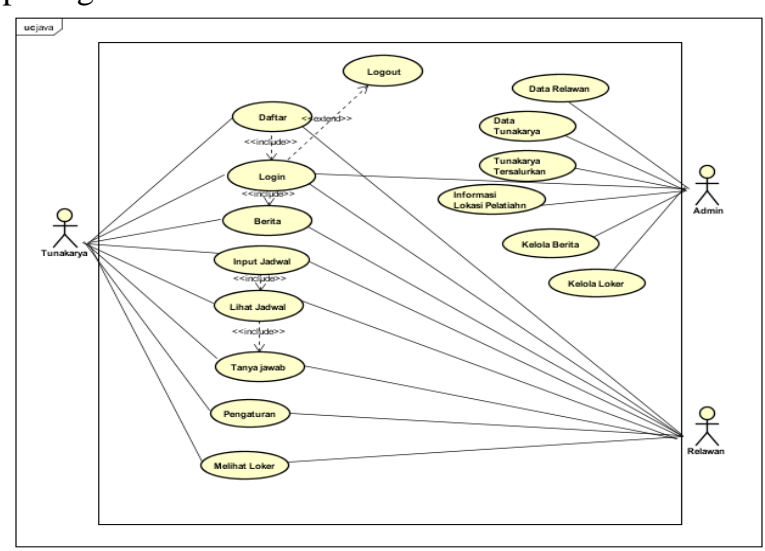

Gambar 1. Model rancangan use case aplikasi GoWork

Aplikasi Go-Work yang dirancang seperti terlihat pada gambar 1 melibatkan 3 aktor, yaitu admin, tunakarya, dan relawan yang dapat dideskripsikan sebagai berikut:

Admin. Admin bertugas mengelola data-data para tunakarya, data relawan, data Tunakarya tersalurkan, mengelola berita-berita terbaru mengenai kegiatan para tunakarya, mengelola lowongan pekerjaaan yang dapat menambahkan dan menghapus lowongan pekerjaan.

Tunakarya. Tunakarya dapat mengakses sistem pelayanan dengan beberapa fitur seperti dapat melakukan pendaftaran, melihat berita terkait dengan kegiatan para tunakarya, menginputkan jadwal pelatihan, melihat jadwal dan lokasi pelatihan, melakukan pengaturan akun, tanya jawab dengan tim relawan atau pembimbing kemudian melihat lowongan kerja dan melamar pekerjaan sesuai dengan keahlianya.

Relawan. Relawan adalah seseorang yang membimbing para tunakarya, dimana para relawan ini memiliki keahlian yang berbeda-beda setiap orangnya. Para relawan dapat melakukan pendaftaran, melihat berita, input jadwal pelatihan, melihat jadwal pelatihan dan lokasi, melakukan pengaturan.

Implementasi model rancangan konseptual pada gambar 1, yang dipisahkan berdasarkan aktor dengan aktifitas yang berbeda-beda sesuai dengan hak akses yang diberikan. Aplikasi yang dikembangkan untuk pengelolaan data dan informasi oleh admin adalah aplikasi berbasis web. Admin dapat melakukan pengelolaan data dan informasi dengan berbagai menu yang disediakan. Tampilan awal aplikasi untuk pengelolaan seperti terlihat pada gambar 2, dan setelah admin berhasil login akan dimunculkan tampilan utama seperti pada gambar 3 .

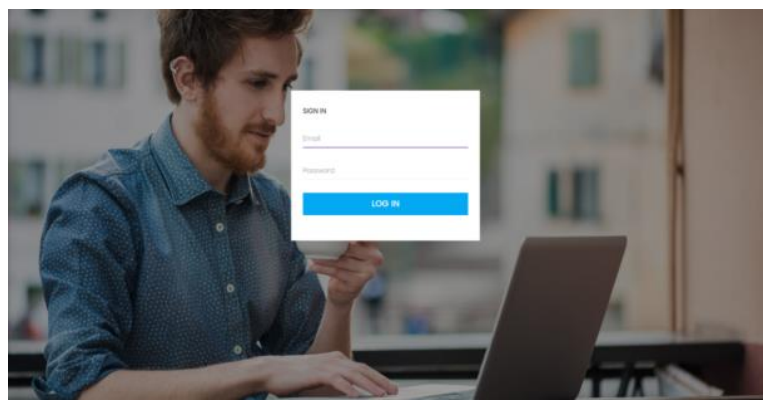

Gambar 2. Tampilan awal aplikasi bagi admin

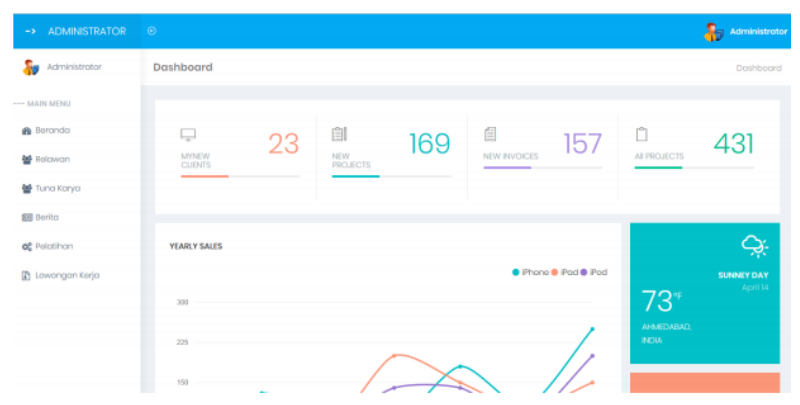

Gambar 3. Tampilan beranda dasbord admin

Fitur-fitur yang dapat digunakan oleh admin untuk mengelola informasi terdapat pada menu utama pada dashbord admin, yaitu menu Beranda, Relawan, Tunakarya, Berita, Pelatihan, dan Lowongan Kerja. Menu Beranda adalah menu utama yang tampil ketika aplikasi dibuka setelah admin login. Menu Relawan digunakan untuk mengelola data relawan yang didalamnya terdapat aktivitas tambah data, edit data, dan hapus data relawan. 


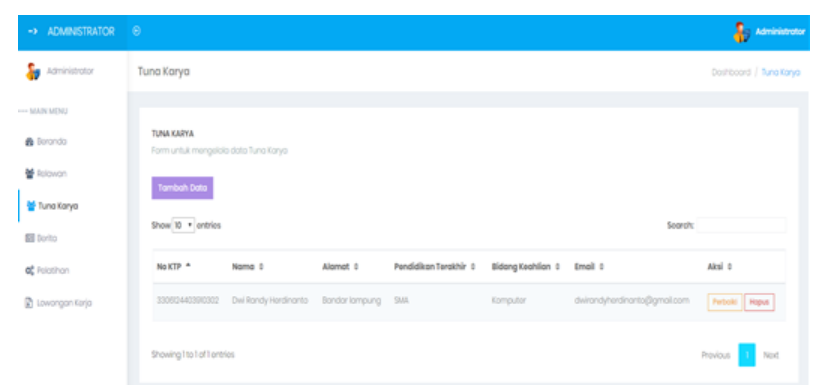

Gambar 4. Tampilan menu tunakarya

Menu Tunakarya digunakan untuk mengelola data tunakarya yang meliputi menambah data, mengedit data, dan menghapus data tunakarya. Tampilan Menu Tunakarya terlihat pada gambar 4.

Menu berita adalah menu yang diberikan untuk memfasilitasi admin menseminasikan berita-berita terkait dengan ketanagakerjaan atau berita yang dianggap perlu untuk disampaikan kepada masyarakat pencari kerja. Dalam form berita terdapat fasilitas untuk untuk menyunting berita dengan menggunakan editor standar yang mudah digunakan (gambar 5). Fasilitas dalam form berita meliputi menambah, mengedit, dan menghapus berita.

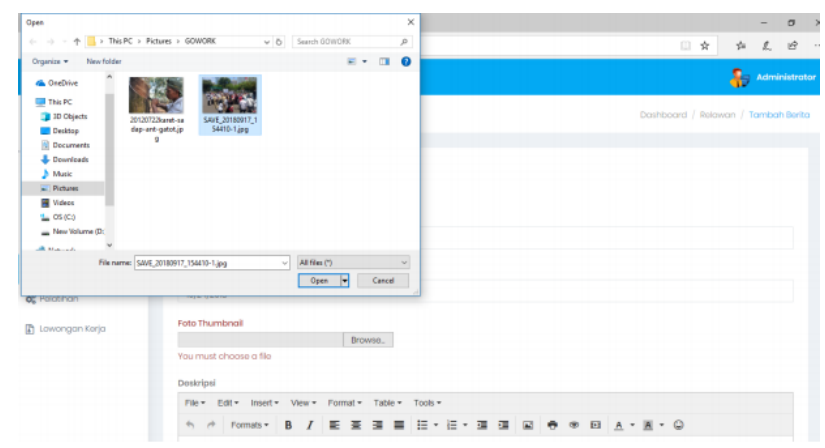

Gambar 5. Editor untuk pengelolaan berita oleh admin

Aplikasi Go-Work dikembangkan secara khusus untuk bisa tanampak pada smartphone berbasis sistem operasi android. Tampilan awal jika aplikasi go-work dibuka adalah seperti pada gambar 6 .

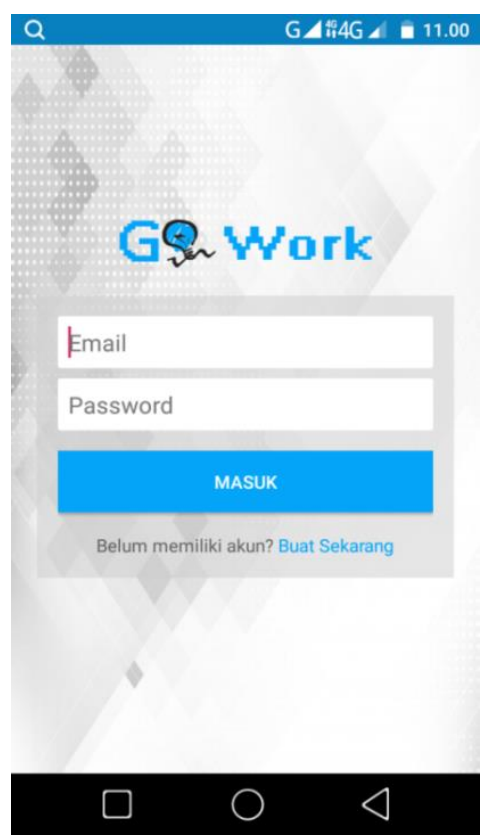

Gambar 6. Tampilan pembuka aplikasi Go-Work

Untuk dapat menggunakan aplikasi Go-Work dan mengakses semua informasi di dallamnya, pengguna harus memiliki akun yang terdaftar pada aplikasi GoWork. Jika sudah memiliki akun pengguna dapat langsung login dan jika belum punya pengguna dapat mendaftar dengan menekan link Buat Sekarang. Tampilan untuk pembuatan akun pada aplikasi Go-Work terlihat pada gambar 7 .

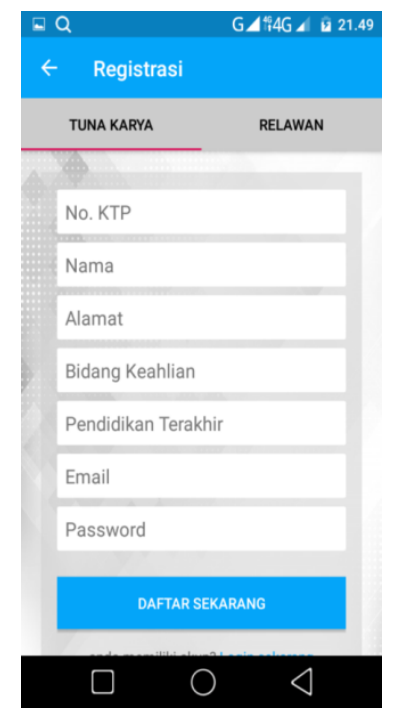

Gambar 7. Form pembuatan akun baru pada aplikasi Go-Work

Berbagai informasi yang dapat diakses oleh pengguna (tunakarya) pada aplikasi Go-Work meliputi berita, informasi pelatihan, informasi lowongan kerja, dan jadwal pelatihan. Aplikasi Go-Work juga memiliki failitas tanya jawab, dimana pengguna dapat menyampaikan pertanyaan yang nanti akan dijawab oleh 
admin atau relawan. Menu utama pada aplikasi Go-Work terdapat pada gambar 8 .

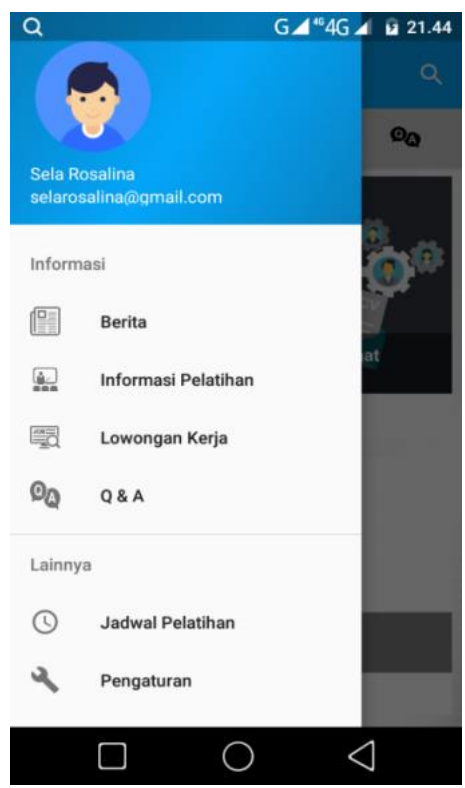

Gambar 8. Menu utama pada aplikasi Go-Work

Menu berita dapat dipilih oleh pengguna jika pengguna ingin mengakses berbagai berita yang sudah di publikasikan oleh admin. Tampilan form berita pada aplikasi Go-Work terdapat pada gambar 9.

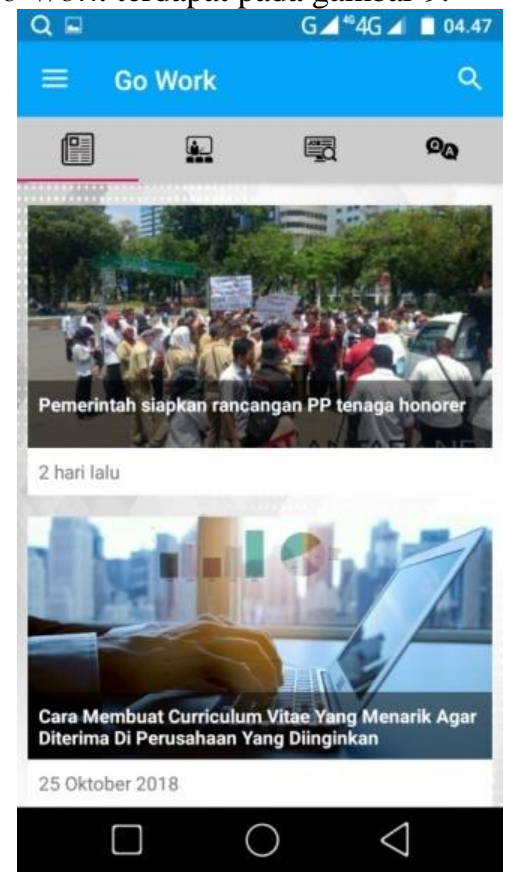

Gambar 9. Tampilan form berita pada aplikasi GoWork

Menu Informasi Pelatihan jika dipilih oleh pengguna akan menampilkan informasi berbagai pelatihan yang diprogramkan dan dapat diikuti oleh para tunakarya (gambar 10).

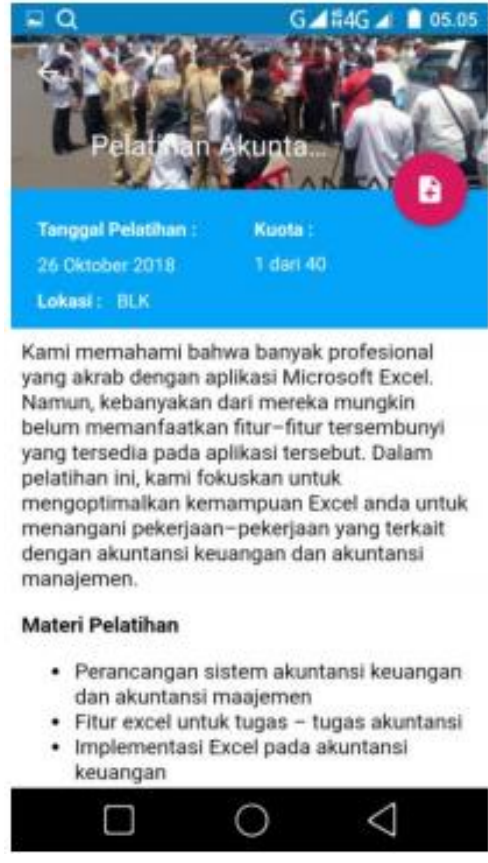

Gambar 10. Tampilan informasi pelatihan pada aplikasi Go-Work

Para pengguna dapat mendaftarkan diri untuk mengikuti pelatihan yang akan dilaksanakan. Jika pengguna sudah mendaftarkan diri untuk mengikuti kegiatan pelatihan, pengguna dapat melihat kegiatan yang akan diikuti pada menu Jadwal Pelatihan (gambar 11).

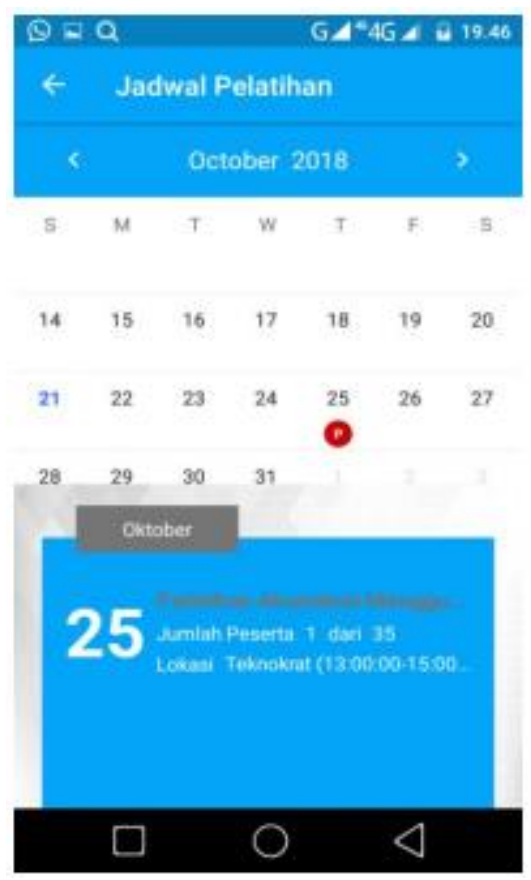

Gambar 11. Tampilan jadwal pelatihan pada aplikasi Go-Work

Menu Lowongan Kerja berisi berbagai informasi mengenai lowongan kerja yang telah didata dan 
dimasukkan oleh admin. Tampilan form lowongan kerja pada aplikasi Go-Work terdapat pada gambar 12 .

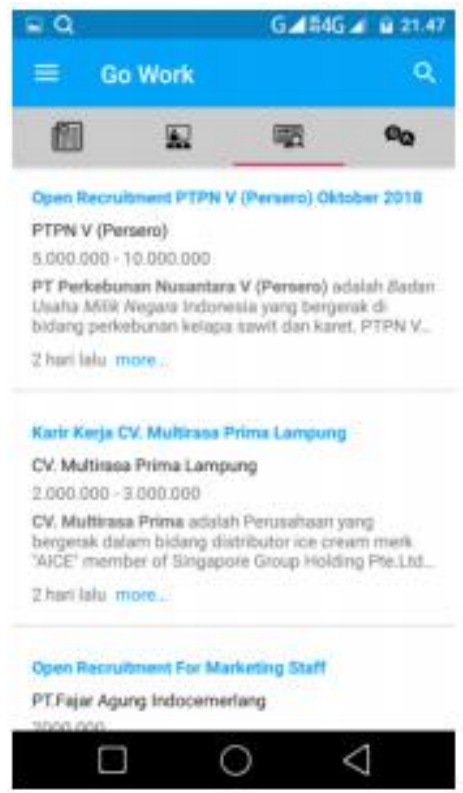

Gambar 12. Form tampilan informasi lowongan pada aplikasi Go-Work.

Pengguna dapat memilih link informasi lowongan kerja untuk mendapatkan informasi lebih detail mengenai lowongan kerja yang ada. Tampilan informasi lowongan detail terlihat pada gambar 13 .

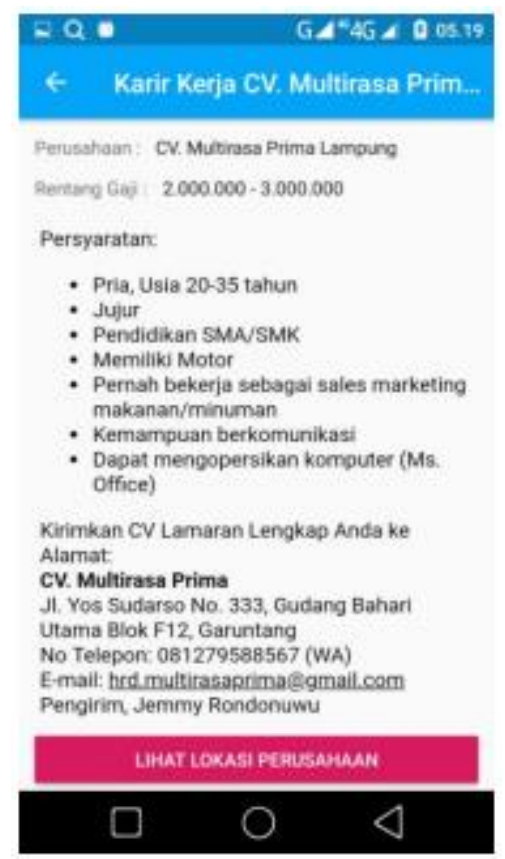

Gambar 13. Informasi detail lowongan pekerjaan pada aplikasi Go-Work

Pengguna aplikasi dapat melihat lokasi perusahaan pada peta yang akan muncul jika ditekan link tombol "LIHAT
LOKASI PERUSAHAAN". Tampilan lokasi perusahaan pada aplikasi Go-Work terdapat pada gambar 14.

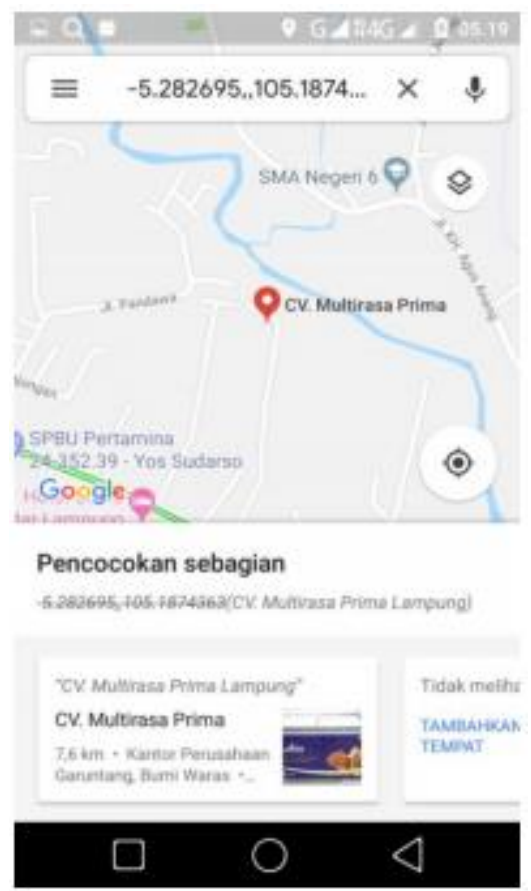

Gambar 14. Tampilan lokasi perusahaan pada menu informasi lowongan kerja

Aplikasi Go-Work juga dilengkapi dengan fasilitas bertanya dan pertanyaan ini akan direspon oleh para relawan yang terdaftar dan admin. Tampilan form untuk mengajukan pertanyaan terdapat pada gambar 15 .

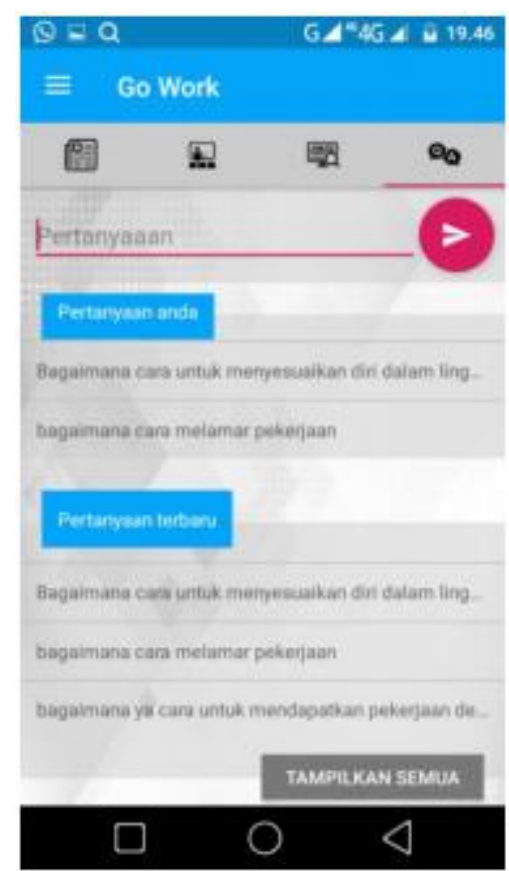

Gambar 15. Tampilan form pengajuan pertanyaan dari pengguna 
Disamping semua fasilitas yang sudah dijelaskan sebelumnya, aplikasi Go-Work juga memberikan fasilitas pengaturan yang dapat digunakan oleh pengguna untuk mengelola akun pribadi masng-masing pengguna.

Berdasarkan hasil survey yang dilaksankaan oleh penulis kepada pengguna aplikasi didapatkan hasil bahwa informasi yang termuat dan failitas yang ada sangat memadai dan membantu Dinas Tenaga Kerja dan Transmigrasi Provinsi Lampung dan pihak terkait. Para Tuna Karya memiliki akses yang mudah untuk mendapatkan informasi-informasi yang dibutuhkan bagi para pencari kerja.

\section{Kesimpulan}

Aplikasi Go-Work telah mampu memenuhi kebutuhan para tunakarya untuk mengakses informasi terkait lowongan kerja, kegiatan pelatihan untuk meningkatkan keterampilan para pencari kerja. Aplikasi Go-Work telah membantu Dinas Tenaga Kerja dan Transmigrasi Provinsi Lampung dalam mendeseminasikan informasi kepada para pencari kerja.

\section{Daftar Pustaka}

DINARAH, S. A., ACHMAD, S., \& IRFANSYAH. (2017, April). Kajian Penggunaan Ponsel Cerdas Berdasarkan Profesi. Jurnal Sosioteknologi, 16(1), 110-124. Retrieved from http://journals.itb.ac.id/index.php/sostek /article/viewFile/3109/2498

N SIRAIT, A. M. (2013, Februari). Analisis beberapa faktor yang berpengaruh terhadap jumlah pengangguran kabupaten/kota di Provinsi Bali. Ejurnal Ekonomi Pembangunan, 2(2), 108-118. Retrieved from https://ojs.unud.ac.id/index.php/eep/arti cle/view/4299

PEBRIYANTI, Y. (2015). Kemas Ulang Informasi: Kumpulan Karya Tulis Ilmiah Peneliti. JURNAL PARI, 1(1), 27-33. Retrieved from http://ejournalbalitbang.kkp.go.id/index.php/JP/article /view/131/129

USMAN, S. (2016). Pengembangan Desa Broadband Terpadu. Jurnal Ilmu Komunikasi, 14(3), 175-184. 